\title{
Article \\ Investigation on a Flow Coupling Rudder for Directional Control of a Low-Aspect Tailless Configuration with Diamond-Shaped Wing
}

\author{
Zhongyuan Liu *(D) and Binqian Zhang *
}

check for updates

Citation: Liu, Z.; Zhang, B. Investigation on a Flow Coupling Rudder for Directional Control of a Low-Aspect Tailless Configuration with Diamond-Shaped Wing. Aerospace 2022, 9, 79. https:/ / doi.org/10.3390/aerospace9020079

Academic Editor: Hirotaka Sakaue

Received: 21 December 2021

Accepted: 29 January 2022

Published: 1 February 2022

Publisher's Note: MDPI stays neutral with regard to jurisdictional claims in published maps and institutional affiliations.

Copyright: (c) 2022 by the authors. Licensee MDPI, Basel, Switzerland. This article is an open access article distributed under the terms and conditions of the Creative Commons Attribution (CC BY) license (https:/ / creativecommons.org/licenses/by/ $4.0 /)$.
School of Aeronautics, Northwestern Polytechnical University, Xi'an 710072, China

* Correspondence: liuzy@mail.nwpu.edu.cn (Z.L.); bqzhang@nwpu.edu.cn (B.Z.)

\begin{abstract}
To solve the issues of directional control and aerodynamic moment coupling for a lowaspect tailless configuration with a diamond-shaped wing, we herein propose the concept of a flow coupling rudder (FCR). The FCR was composed of two basic control surfaces: a spoiler slot deflector (SSD) on the upper surface of the wing and the corresponding elevon. With the constraints of the fixed area and spanwise position of the SSD, the effects of the leading-edge sweep angle, chord position of the SSD, and collocating deflection angles of the SSD and elevon on the control characteristics of the configuration were analyzed using a numerical method. Based on the analysis, the selection principle of the key parameters for designing the FCR for the configuration was proposed. This proves that the leading edge of the selected SSD should be swept back instead of being parallel to the trailing edge of the wing to design an FCR with favorable aerodynamic performance for such a configuration. By accurately adjusting the parameters of the SSD and elevon, the FCR on the one-side wing could supply an effective yawing moment while simultaneously weakening or even eliminating the coupling pitching and rolling moments of traditional drag-type control surfaces. In this study, we provide a method for the directional control surface design of a low-aspect tailless configuration with a diamond-shaped wing.
\end{abstract}

Keywords: low-aspect ratio wing; diamond-shaped wing; tailless configuration; directional control; flow coupling rudder; numerical simulation

\section{Introduction}

Low-aspect tailless configurations with diamond-shaped wings have become the focus of advanced fighter research owing to their superior aerodynamic performance, good stealth performance, and easy integration arrangement [1-4]. However, the lack of a conventional tail wing poses a serious challenge to the directional control of the tailless configuration.

For the yaw-control issue of the tailless configuration, considerable research has been carried out. In 1993, the United States Air Force developed an innovative control effector program for tailless fighter configurations with the objective of researching control surfaces. The first phase of the program studied innovative control devices, including all moving wingtips (AMTs), differential leading-edge flaps (DLEFs), SSDs, deployable rudders (DRUDs), and lower surface spoilers (LSPs). The second phase involved the wind tunnel and numerical simulation of the control surfaces. The results showed that drag-type control devices have the potential for yaw control [5-7]. AMTs can provide a satisfactory yawing moment to meet the directional control requirements of an aircraft, cooperating with its trailing-edge control surface; however, it is also accompanied by large longitudinal and lateral moments [8,9]. Although DLEF has the capacity to proceed with yaw control, it lacks efficiency [10]. The split-drag-rudder is an effective directional control effector, while there exists a severe three-axis control coupling effect [11]. The forebody asymmetric nosestrake was also a result-oriented yaw-control effector by producing an asymmetric nose 
vortex, but simultaneously, it increased the nose-up moment distinctly [12-14]. In addition, the Royal Institute of Technology $(\mathrm{KTH})$ proposed the concept of yaw control by differential flaps on a tailless configuration based on a wind tunnel test [15]. Although the differential flaps could offer a satisfactory yawing moment, the method occupied the trailing-edge rudders, possibly influencing the longitudinal or lateral control by trailing-edge rudders, especially for low-aspect aircraft [16]. Moreover, the adoption of SSD alone could provide a considerable yawing moment, but the rolling and pitching moments were coupled owing to the changes in lift and drag caused by SSD. Therefore, the concept of a combined control surface (CCS) comprising an SSD and the elevon was proposed. Related research has demonstrated that CCS can offer a satisfactory yawing moment and decrease the coupling rolling and pitching moments [16-18]. Although there has been significant research on CCS formed by SSD and elevon for tailless configurations, these studies mainly focused on wings with a sweptback trailing edge and lacked related parameter investigations. Consequently, there is less similar research on directional control for a low-aspect tailless configuration with the diamond-shaped wing adopted by most fighters.

Aiming at the yawing control issue of low-aspect tailless configurations with a diamond-shaped wing and the issue that the existing drag-type directional control surfaces can easily couple rolling and pitching moments, the concept of FCR composited of SSD and the corresponding elevon based on flow coupling is proposed herein. The model studied in this paper, the numerical method, and validation are showed in Section 2. Section 3 examines the aerodynamic performance of the configurations when the yaw-control surface is adopted alone. Section 4 analyzes the three-axis aerodynamic moment characteristics of the configurations with different parameters of FCR, including the leading-edge sweep angles, chord positions of the SSD, and the collocating deflection angles of the SSD and elevon. Subsequently, the parameter influences, flow mechanism, and parameter selection principles are studied. Finally, Section 5 provides concluding statements.

\section{Numerical Method and Model}

\subsection{Research Model}

Figure 1 shows the model used herein. The configuration comprises a diamond-shaped wing and lift-fuselage with a sharp leading-edge strake. The wing has a leading-edge backswept angle of $52^{\circ}$ and a trailing-edge forward-swept angle of $30^{\circ}$. On the upper surface, a modified top-mounted inlet, and two engine bumps are arranged. Some of the main parameters of the configuration are listed in Table 1.

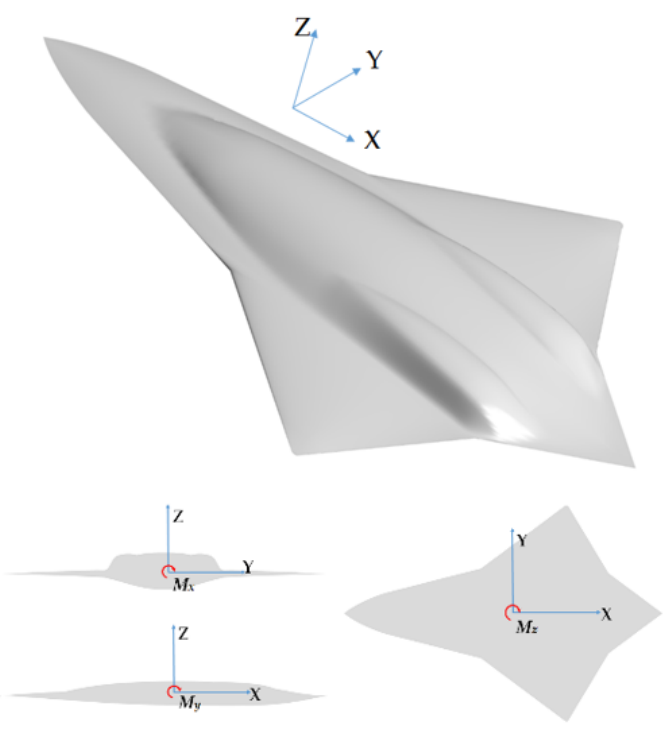

Figure 1. The coordinate system and sign convention for the research model. 
Table 1. Main parameters of the configuration and control surface.

\begin{tabular}{cc}
\hline Parameter & Value \\
\hline Aspect ratio & 1.7 \\
Wingspan $(\mathrm{m})$ & 12 \\
Total Length $(\mathrm{m})$ & 18.9 \\
SSD Width $W_{e}(\mathrm{~m})$ & 1.6 \\
Elevon Width $W_{s}(\mathrm{~m})$ & 1.5 \\
Position Parameter $C_{x}(\mathrm{~m})$ & 1.1 \\
SSD Area $\left(\mathrm{m}^{2}\right)$ & 1.33 \\
Elevon Area $\left(\mathrm{m}^{2}\right)$ & 1.26 \\
Reference Area $\left(\mathrm{m}^{2}\right)$ & 86 \\
\hline
\end{tabular}

According to references [5-7], an elevon and three different SSDs (SSD1, SSD2, and SSD3) are primarily designed. The positions of the control surfaces are shown in Figure 2, and some related parameters are displayed in Table 1 , in which $W_{e}$ and $W_{s}$ are the widths of the elevon and SSDs, and $C_{x}$ (Position Parameter) is the length from the wing tip to the outer end face of control surface, respectively. To reduce the influence of the control surface on the radar stealth performance of an aircraft, the trailing edges of SSDs are all parallel to the trailing edges of the main wings [3]. The area, length, and spanwise position of the three SSDs remained unchanged. The elevon is located behind the SSD. The leading edge of the elevon is parallel to the trailing edge of the wing, and the area is slightly smaller than the drag rudder. The baseline configuration is the one with no deflection on the control surface. In addition, it is assumed that the cavity caused by unfolding the SSD can be ignored because the SSD thickness is relatively small.

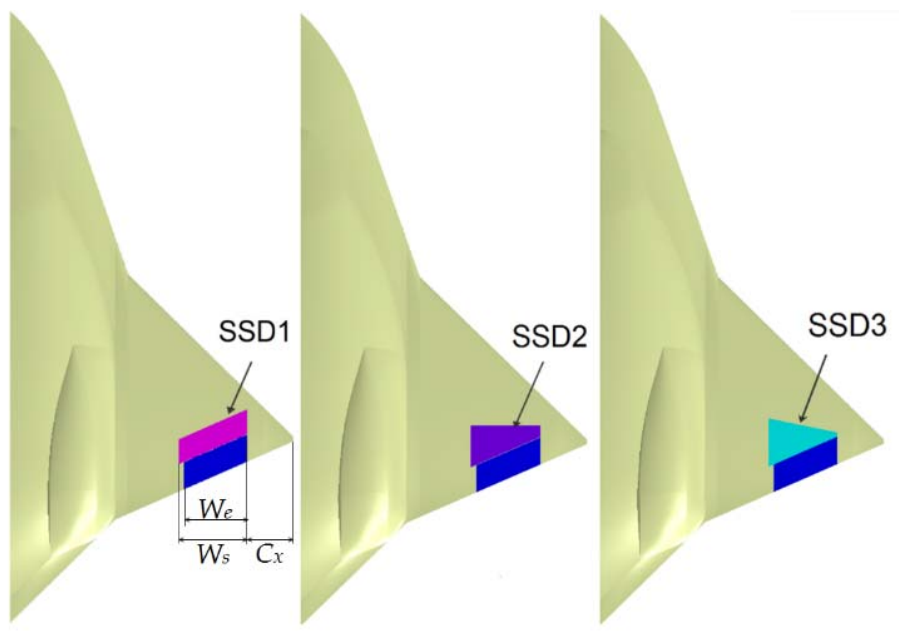

Figure 2. Positions of different control surfaces.

Several aerodynamic parameters are defined according to the reference [19]. Angle of attack $(\alpha)$ is defined as the angle between the main chord and the freestream velocity. Other concerned coefficients are defined as follows:

$$
\begin{aligned}
& C_{L}=\frac{L}{\frac{1}{2} \rho_{\infty} v_{\infty}^{2} S_{r e f}} \\
& C_{D}=\frac{D}{\frac{1}{2} \rho_{\infty} v_{\infty}^{2} S_{r e f}} \\
& C_{l}=\frac{M_{x}}{\frac{1}{2} \rho_{\infty} v_{\infty}^{2} S_{r e f} \frac{b}{2}}
\end{aligned}
$$




$$
\begin{aligned}
C_{m} & =\frac{M_{y}}{\frac{1}{2} \rho_{\infty} v_{\infty}^{2} S_{r e f} c} \\
C_{n} & =\frac{M_{z}}{\frac{1}{2} \rho_{\infty} v_{\infty}^{2} S_{r e f} \frac{b}{2}}
\end{aligned}
$$

where $C_{L}, C_{D}, C_{l}, C_{m}$, and $C_{n}$ denote the coefficients of lift, drag, rolling moment, pitching moment, and yawing moment, respectively. $L$ and $D$ are lift force and drag force, while $M_{x}, M_{y}$, and $M_{z}$ are the rolling moment, pitching moment, and yawing moment, as shown in Figure 1. Furthermore, $\rho_{\infty}$ and $v_{\infty}$ are the density and velocity of the freestream, and $c, b$, and $S_{r e f}$ are mean aerodynamic chord, wingspan, and reference area of the aircraft, respectively. In this study, right-yawing, right-rolling, and nose-up moments were positive while left-yawing, left-rolling and nose-down moments were negative.

\subsection{Numerical Method and Verification}

The calculations in this study were conducted using the ANSYS CFX platform. The numerical method was based on the finite volume approach to solve the Reynolds Averaged Navier-Stokes (RANS) equations. The second-order central difference scheme was adopted to discretize the viscous term. Time discretization was accomplished using the second-order Euler scheme. The Shear Stress Transport (SST) model was selected as the turbulence model owing to its simulative capacity of flow separation, which is the common flow phenomenon of a configuration with a control surface [20]. Free-flow and no-slip boundary conditions were separately assigned to the far-field surfaces and all solid surfaces.

Configuration 8 of the NASA Trap-wing models was selected as the standard model for verification. The deflection angles of the leading-edge slat and trailing-edge flap were $30^{\circ}$ and $20^{\circ}$, respectively. The calculation conditions were $\mathrm{Ma}=0.2$ and $\operatorname{Re}=4.3 \times 10^{6}$, which were the same as those of the wind tunnel [21]. The computational angles of attack $(\alpha)$ ranged from $-4^{\circ}$ to $28^{\circ}$, and the spacing was $4^{\circ}$.

A multi-block structured H-H-type grid with approximately 6,000,000 grid nodes was generated, with an O-type mesh around the model. The grid grew by 1.2 with a $y^{+}$of 1 . The far field was twenty times the length of the mean aerodynamic chord. The surface grid of the model is showed in Figure 3 and $\eta$ is the dimensionless spanwise position of the selected section.

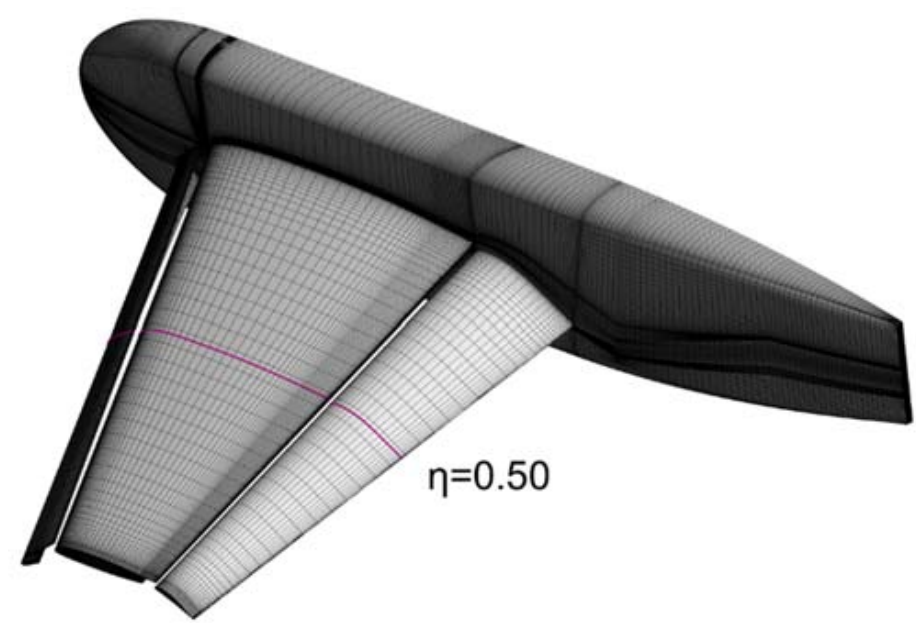

Figure 3. Surface grid of NASA Trap-wing Configuration 8.

Using the above numerical method and grid, calculation results (CFD) were obtained, while the experimental (EXP) results were obtained from reference [20]. Figure 4a,b show the comparison of the lift coefficient $\left(C_{L}\right)$ and drag coefficient $\left(C_{D}\right)$ between the numerical simulation and wind tunnel test of Configuration 8 . The results show that the aerodynamic forces at small and medium angles of attack are in good agreement, while there are dif- 
ferences between the numerical simulation and wind tunnel test results at high angles of attack, which may be related to the vortex breakdown or possibly unsteady effects [22]. A comparison of the pressure coefficient $\left(C_{p}\right)$ distributions of the typical section is shown in Figure $4 c, d$. Despite a slight difference, the $C_{p}$ distributions of CFD and EXP were almost identical. Therefore, it can be confirmed that the numerical method applied herein can effectively predict the aerodynamic performance of a configuration with control surfaces.

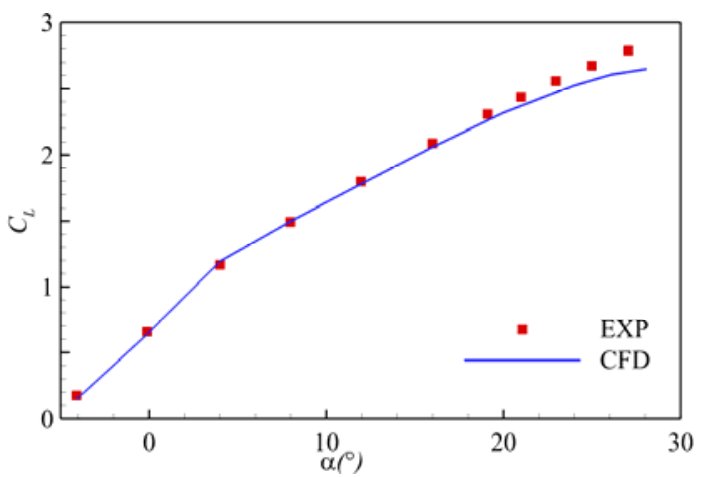

(a)

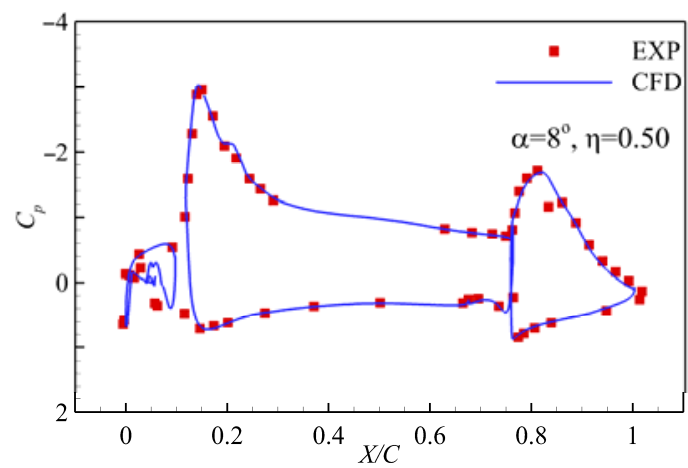

(c)

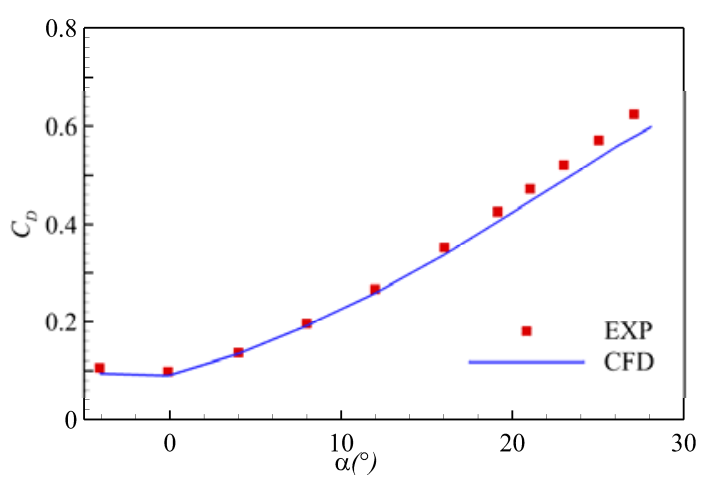

(b)

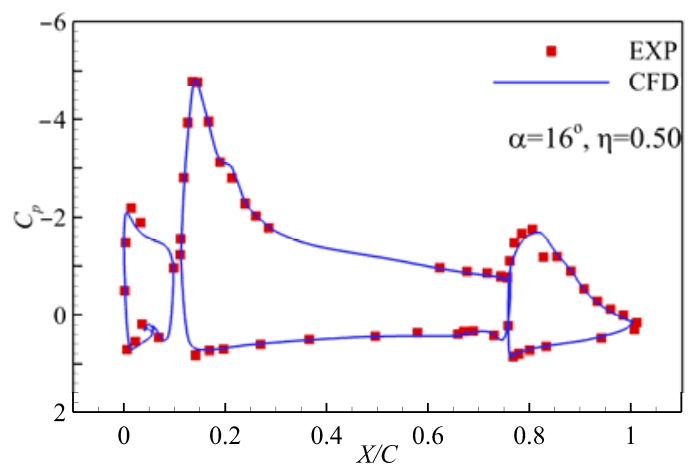

(d)

Figure 4. Comparison results of the experiment and CFD calculation of NASA Trap-wing Configuration 8 for Ma $=0.2, \operatorname{Re}=4.3 \times 10^{6}:$ (a) Lift curve; (b) Drag curve; (c) $C_{p}$ comparison, $\alpha=8^{\circ} ;(\mathbf{d}) C_{p}$ comparison, $\alpha=16^{\circ}$.

\subsection{Grid Convergence Study}

To conduct the numerical simulations, multi-block structured grids with $\mathrm{H}-\mathrm{H}$ topology were generated for the right semi-span of the configurations using ANSYS ICEM CFD mode; the far field was twenty times the mean aerodynamic chord length. A grid convergence study was conducted using the configuration with the elevon and SSD deflected at $\mathrm{Ma}=0.2$ and $\alpha=6^{\circ}$. Five different grids with 2,232,337 cells, 4,595,910 cells, 8,067,578 cells, $16,272,734$ cells, and 32,344,411 cells, respectively, were employed with the same computing domain and grid topology. The result is displayed in Figure 5: $C_{L}$ and $C_{D}$ tended to converge with the cells number increasing, and the grid with about 8 million cells was selected for the computation. The grid had an O-type mesh around the model with a grid growth rate of 1.2 and a $y^{+}$of 1 . As shown in Figure 6, grid refinement was employed in typical regions such as the leading edges, trailing edges, and control surfaces. In the calculation in this study, the configurations with different deflection angles of the control surface adopted the same grid topology and grid node distribution to reduce the influence of grid changes. The computational conditions were $\mathrm{Ma}=0.2$ and $\mathrm{Re}=3.98 \times 10^{7}$, which is a typical lowaltitude maneuvering state for the studied aircraft herein according to the reference [23,24]. In addition, the grids of the baseline configuration and the configurations with different control surface deflections were patched in CFX to obtain the yawing, rolling, and pitching moments. By reflection option in CFX, the grid of baseline was placed on the left side, while 
the grid of the other configuration was on the right side. The Interface function of CFX-Pre was used, and the symmetry faces of the two grids could be set as Interface Side1 and Side2, correspondingly, for the node distributions of the symmetry faces were identical.

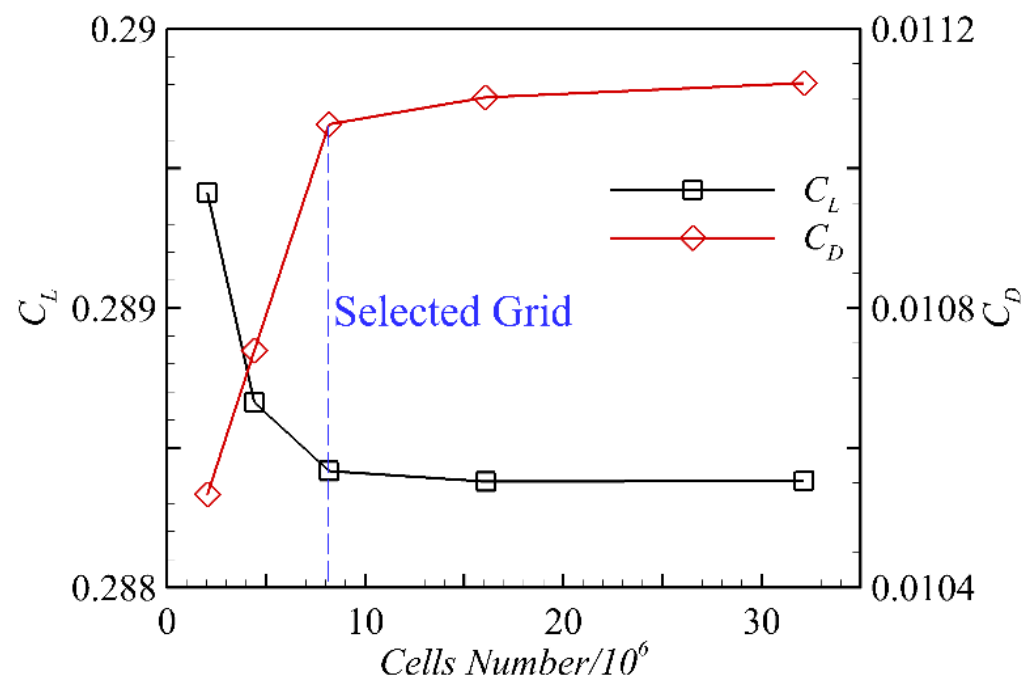

Figure 5. Grid convergence study at $\mathrm{Ma}=0.2, \alpha=6^{\circ}$.

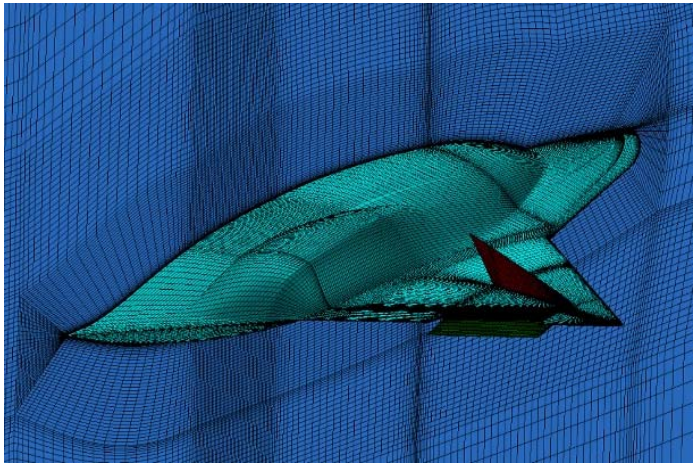

(a)

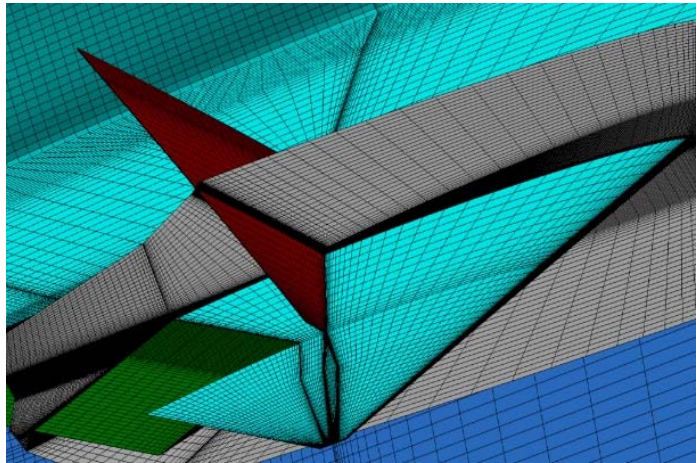

(b)

Figure 6. Computation grid for the studied model: (a) Surface mesh; (b) Mesh around the control surfaces.

\section{Control Characteristics of Single Rudder}

\subsection{Elevon}

The FCR studied herein still adopted the traditional elevon. Although the shape and deflection mode of the elevon did not change, the elevon deflected together with the SSD, generating the coupling flow that directly determines the aerodynamic performance of the FCR. Therefore, analyzing and mastering the aerodynamic characteristics of the elevon is necessary.

In this study, right-wing control surfaces of the configuration were selected as the research objects. When the right elevon deflects downward, the wing trailing-edge local curvature increases, and the lift and drag on the right side of the aircraft increase simultaneously. The difference between the drag and lift on both sides of the configuration will produce the yawing moment $C_{n}$ and couple the rolling moment $C_{l}$, which will also lead to a change in the pitching moment $C_{m}$. To quantify the coupling effect of the control surface deflections, the longitudinal and lateral coupling effect factors $\gamma_{p}$ and $\gamma_{r}$ are defined as follows:

$$
\gamma_{p}=\left|\frac{C_{m}-C_{m 0}}{C_{n}}\right|
$$




$$
\gamma_{r}=\left|\frac{C_{l}}{C_{n}}\right|
$$

where $C_{m 0}$ is the pitching moment of the baseline configuration, and $C_{m}, C_{n}$, and $C_{l}$ denote the pitching moment, yawing moment, and rolling moment of the configurations with the deflected control surfaces, respectively. The coupling effect factor can clearly obtain the relation between the yaw moment and the coupled rolling and pitching moments when the control surfaces deflect. The smaller the coupling effect factors, the weaker are the coupling effects, which are more conducive to decoupling.

Figure 7 shows the three-axis moments of the elevons with deflection angles of $15^{\circ}$ and $30^{\circ}$. The yawing moments provided by the elevon change gently as the angle of attack increases, coupled with a large reverse rolling moment and nose-down moment, making the pitching moments smaller than those of the baseline configuration. The yawing moment and rolling moment generated by the elevon increased with an increase in the deflection angle; however, when the deflection angle was $30^{\circ}$, the rolling moment increased nonlinearly after an angle of attack of $12^{\circ}$, which was mainly caused by the failure of the elevon due to flow separation.

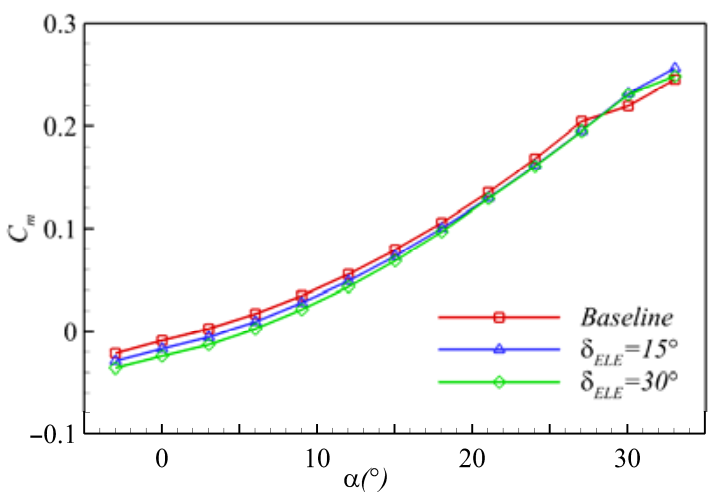

(a)

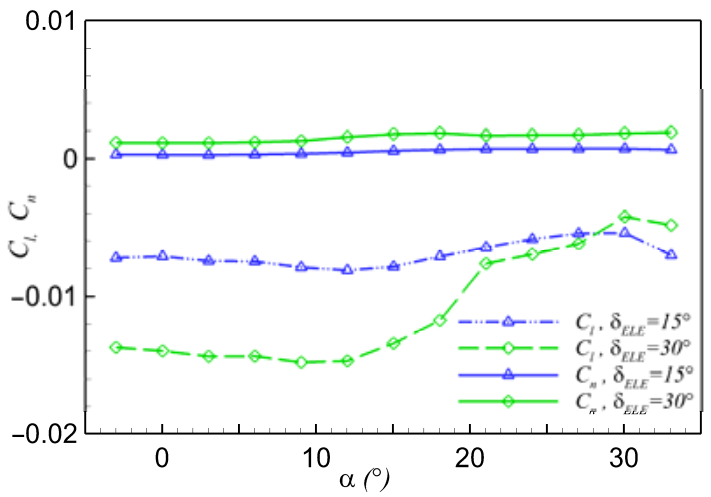

(b)

Figure 7. Control characteristics when the elevon deflects alone for $\mathrm{Ma}=0.2, \operatorname{Re}=3.98 \times 10^{7}$ : (a) Pitching moment; (b) Rolling and yawing moments.

Table 2 lists the moments when the elevon is deflected downward at $\alpha=6^{\circ}$. The yawing moment is 0.00032 , the pitching moment variation is -0.00761 , the coupled rolling moment is -0.00749 , and the $\gamma_{p}, \gamma_{r}$ are approximately 23.40 and 23.78 , respectively. The results show that the yaw moment provided by deflecting the elevon is small, and it is strongly coupled with longitudinal and lateral control. Therefore, it is not suitable to use the elevon alone as a directional control surface.

Table 2. Aerodynamic moments characteristics of the elevon at $\alpha=6^{\circ}$.

\begin{tabular}{cccc}
\hline Case & Moment & Value & $\gamma_{p}$ or $\gamma_{r}$ \\
\hline \multirow{2}{*}{$\delta_{\mathrm{ELE}}=15^{\circ}$} & $C_{n}$ & 0.00032 & - \\
& $C_{l}$ & -0.00749 & 23.78 \\
& $\triangle C_{m}$ & -0.00761 & 23.40 \\
\hline \multirow{2}{*}{$\delta_{\mathrm{ELE}}=30^{\circ}$} & $C_{n}$ & 0.00120 & - \\
& $C_{l}$ & -0.01437 & 11.49 \\
& $\triangle C_{m}$ & -0.01463 & 12.19 \\
\hline
\end{tabular}

\subsection{Spoiler Slot Deflector}

Although SSD is a thin plate, the windward area is increased when the SSD on the upper surface of the right-wing is unfolding. As a result, the drag on the right side increased. The difference in drag on both sides of the aircraft produces a yawing moment. Meanwhile, 
when the SSD unfolds, the flow needs to bypass the SSD, resulting in flow separation behind it. Hence, the local speed and negative pressure were reduced, resulting in the loss of lift of the right-wing. Therefore, the yawing moment generated by unfolding the SSD is coupled with the rolling moment, accompanied by a change in the pitching moment.

Based on the control mechanism of the SSD, in this section, we study the influence of the leading-edge sweep angle of the SSD on the control characteristics. When the leading edge of the SSD sweeps backward, the sweep angle $\Lambda>0$ and $\Lambda<0$ when the leading-edge sweeps forward. For the configuration with the diamond-shaped wing studied herein, three SSDs with different leading-edge sweep angles were designed: $\operatorname{SSD} 1\left(\Lambda=-30^{\circ}\right)$, $\operatorname{SSD} 2\left(\Lambda=0^{\circ}\right)$, and $\operatorname{SSD} 3\left(\Lambda=15^{\circ}\right)$.

The aerodynamic moment characteristics of the three SSDs are shown in Figure 8 when they unfold by $45^{\circ}$. The SSDs can produce right-yawing and right-rolling moments, and the change in pitch moment is not obvious. Table 3 shows the descriptions of control characteristics for the three SSDs at different $\alpha$.

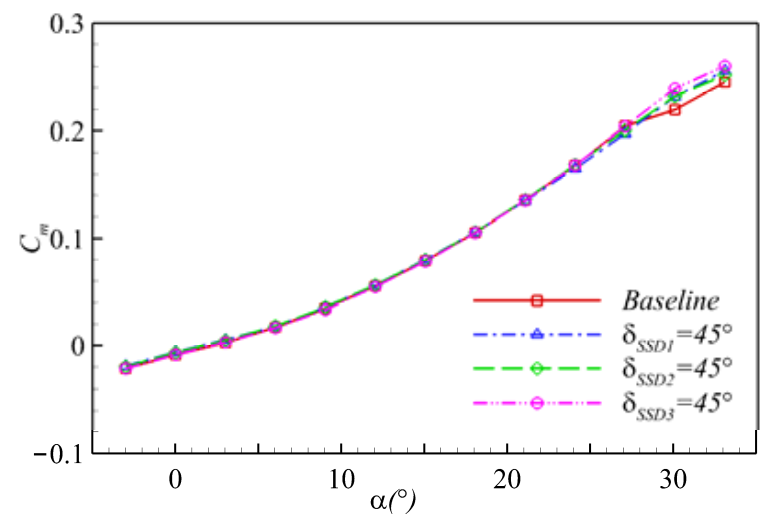

(a)

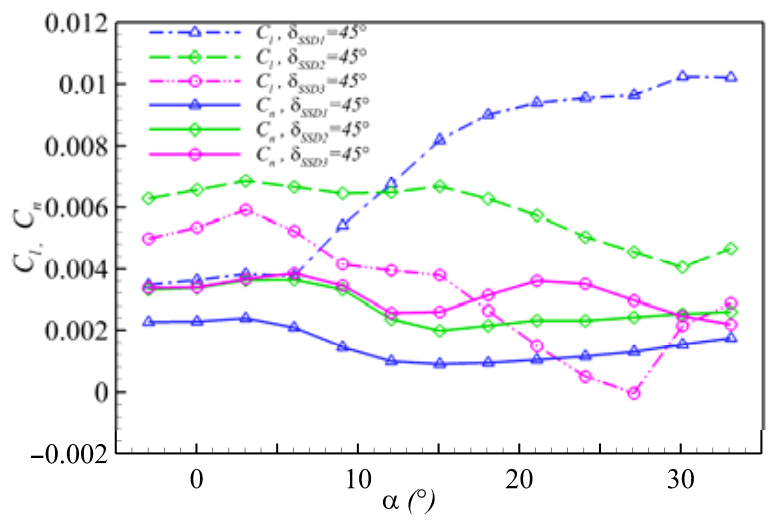

(b)

Figure 8. Control characteristics when the three SSDs unfold by $45^{\circ}$ alone for $\mathrm{Ma}=0.2$, $\operatorname{Re}=3.98 \times 10^{7}:$ (a) Pitching moment; (b) Rolling and yawing moments.

Table 3. Descriptions of control characteristics for the three SSDs.

\begin{tabular}{|c|c|c|c|}
\hline \multirow{2}{*}{ Case } & \multicolumn{3}{|c|}{ Descriptions } \\
\hline & $C_{n}$ & $C_{l}$ & $\gamma_{r}$ \\
\hline SSD1 & $\begin{array}{c}\alpha \leq 3, \text { increase slowly; } \\
3^{\circ} \leq \alpha \leq 12^{\circ}, \text { decrease significantly; } \\
\alpha \geq 12^{\circ}, \text { increase slowly. }\end{array}$ & $\begin{array}{c}\alpha \leq 6, \text { increase slowly; } \\
\alpha \geq 6, \text { increase obviously. }\end{array}$ & $>1$ \\
\hline SSD2 & $\begin{array}{l}\text { Similar trendency with SSD1; } \\
\text { Larger than } C_{n} \text { of SSD1. }\end{array}$ & $\begin{array}{c}\alpha \leq 12^{\circ}, \text { change slowly, } \\
\alpha \geq 12^{\circ}, \text { decrease obviously; } \\
\alpha \leq 9^{\circ} \text {, larger than } C_{l} \text { of SSD1, } \\
\alpha \geq 12^{\circ} \text {, less than } C_{l} \text { of SSD1. }\end{array}$ & $>1$ \\
\hline SSD3 & $\begin{array}{c}\text { Similar trendency with SSD1; } \\
\alpha \leq 9^{\circ} \text {, almost equivalent to } C_{n} \text { of SSD2, } \\
\alpha \geq 12^{\circ}, \text { Larger than } C_{n} \text { of SSD2. }\end{array}$ & $\begin{array}{c}\alpha \leq 3, \text { increase slowly, } \\
\alpha \geq 3^{\circ}, \text { decrease obviously; } \\
\text { less than } C_{l} \text { of SSD2. }\end{array}$ & $\begin{array}{l}\mathrm{A}<18^{\circ},>1 \\
\alpha \geq 18^{\circ},<1\end{array}$ \\
\hline
\end{tabular}

Figure 9 shows the spatial streamlines near the three SSDs when they unfold by $45^{\circ}$ at $\alpha=6^{\circ}$. The separation regions behind SSD2 and SSD3 are significantly larger than those behind SSD1, resulting in greater drag variation and, consequently, a greater yawing moment. Table 4 lists the moments when the SSDs unfold by $45^{\circ}$ at $\alpha=6^{\circ}$. Table 5 compares the aerodynamic moments characteristics of the elevon and SSDs at $\alpha=6^{\circ}$. Although the coupling effect factors are much smaller than those of the elevon, the values are still considerable, indicating that there exists an issue of aerodynamic moment coupling for the configurations. 


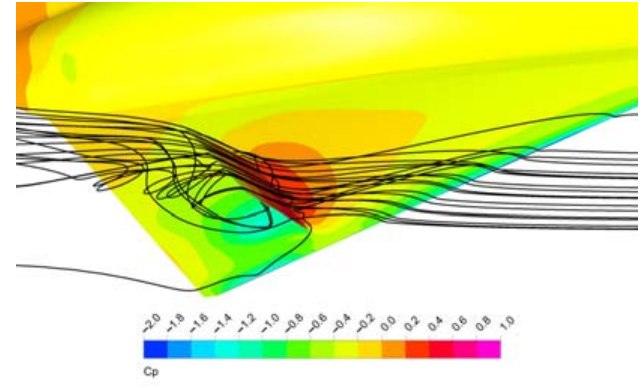

(a)

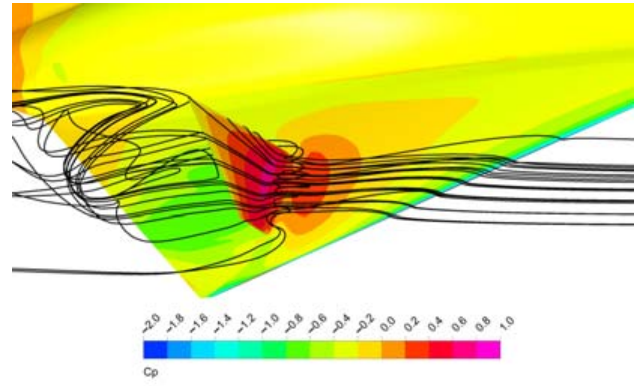

(b)

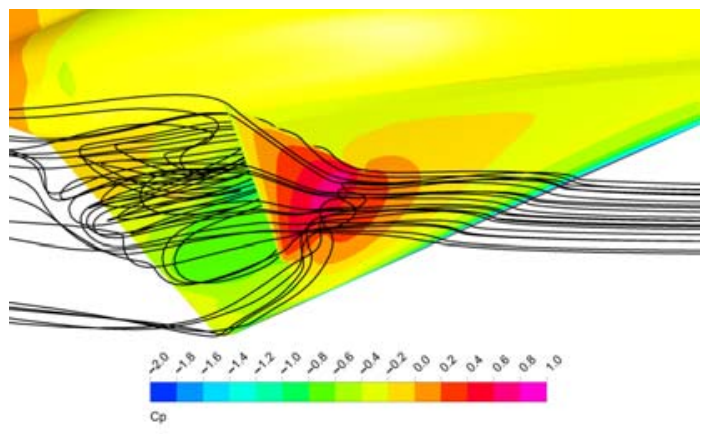

(c)

Figure 9. Spatial streamlines near the control surface and $C p$ distributions around SSDs, $\mathrm{Ma}=0.2$ $\operatorname{Re}=3.98 \times 10^{7}, \alpha=6^{\circ}:(\mathbf{a}) \operatorname{SSD} 1 ;(\mathbf{b}) \operatorname{SSD} 2 ;$ (c) SSD3.

Table 4. Aerodynamic moments characteristics of the SSDs at $\alpha=6^{\circ}$.

\begin{tabular}{cccc}
\hline Case & Moment & Value & $\gamma_{p}$ or $\gamma_{r}$ \\
\hline \multirow{2}{*}{$\delta_{\text {SSD1 }}=45^{\circ}$} & $C_{n}$ & 0.00209 & - \\
& $C_{l}$ & 0.00378 & 1.80 \\
& $\triangle C_{m}$ & 0.00104 & 0.48 \\
\hline$\delta_{\text {SSD2 }}=45^{\circ}$ & $C_{n}$ & 0.00364 & - \\
& $C_{l}$ & 0.00667 & 0.36 \\
\hline$\delta_{\text {SSD3 }}=45^{\circ}$ & $\triangle C_{m}$ & 0.00130 & - \\
& $C_{n}$ & 0.00385 & 1.36 \\
\hline
\end{tabular}

Table 5. Comparison between the elevon and SSDs at $\alpha=6^{\circ}$.

\begin{tabular}{cccc}
\hline Case & $C_{n}$ & $\gamma_{p}$ & $\gamma_{r}$ \\
\hline$\delta_{\mathrm{ELE}}=15^{\circ}$ & 0.00032 & 23.40 & 23.78 \\
$\delta_{\mathrm{ELE}}=30^{\circ}$ & 0.00120 & 12.19 & 11.49 \\
$\delta_{\mathrm{SSD} 1}=45^{\circ}$ & 0.00209 & 0.48 & 1.80 \\
$\delta_{\mathrm{SSD} 2}=45^{\circ}$ & 0.00364 & 0.36 & 1.83 \\
$\delta_{\mathrm{SSD} 3}=45^{\circ}$ & 0.00385 & 0.12 & 1.36 \\
\hline
\end{tabular}

From the above analysis, it can be inferred that for a tailless configuration with a diamond-shaped wing, the yawing moment provided by the SSD with the leading edge parallel to the trailing edge of the main wing is limited, and the coupled rolling moment will increase nonlinearly. At high angles of attack, the rolling moment is much greater than the yawing moment, which is unfavorable for flight stability. The SSDs with leading-edge sweptback angles of $0^{\circ}$ and $15^{\circ}$ can provide a stronger yawing moment, and the rolling moments are smaller at high angles of attack. SSDs have more effective directional control 
than elevons, but they are coupled with lateral control. Consequently, utilizing the SSD alone could not offer satisfactory control characteristics, and a decoupling design is needed in subsequent studies.

\section{Investigation on Flow Coupling Rudder}

The tailless configurations cancel the vertical tail, which can generate lateral force to control the direction, and use deflecting one-side control surfaces to increase the one-side drag to produce the yawing moment. The analysis of the above section leads to an inference that when the SSDs and elevon are adopted for yawing control alone, they will produce simultaneous coupling of the yaw moment and greater rolling moment, thereby causing a change in the pitching moment. The coupling effect will have an adverse impact on attitude control; therefore, carrying out a decoupling design is necessary. The results show that when the right-side elevon deflects downward, the lift and drag increase simultaneously, resulting in a right-yawing moment and a coupled reverse rolling moment; when the right-side SSD is unfolding, the drag increases while the lift decreases, resulting in a rightyawing moment coupled with a right-rolling moment. Therefore, a flow coupling rudder composed of an SSD and its rear elevon is proposed for directional control. By adjusting the matching parameters of the elevon and SSD, the flow coupling between the SSD and elevon can produce the ideal effect of increasing drag and constant lift, which could improve the yawing moment and suppress or even eliminate the coupled rolling and pitching moment.

\subsection{Flow Coupling Mechanism of FCR}

To verify the effectiveness of the concept of FCR, elevon and three different SSDs compose three different FCRs. Figure 10 compares the lateral and directional control characteristics of the FCRs, corresponding SSDs, and elevons. From the comparison results, after the coupling design of the control surfaces, the yawing moments increase and the rolling moments decrease.

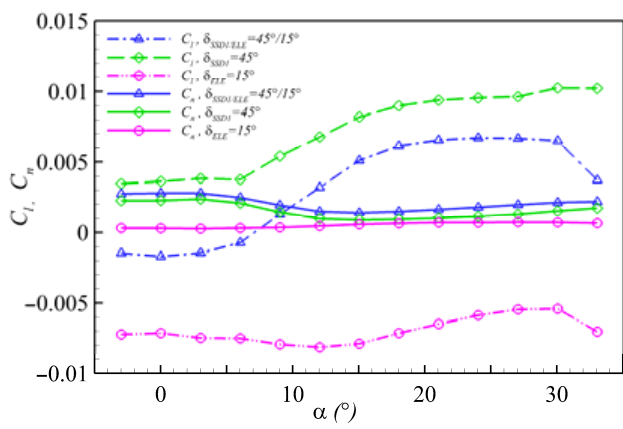

(a)

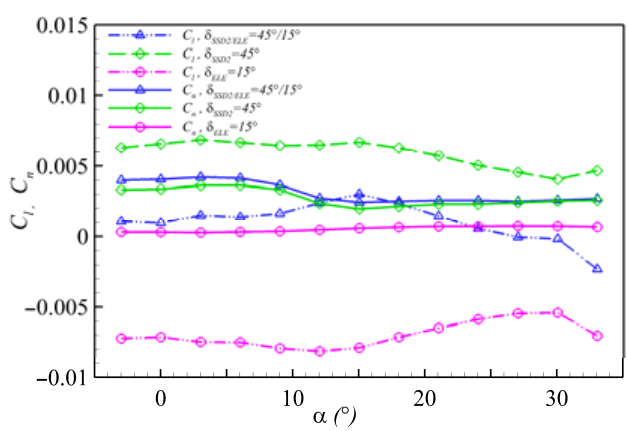

(b)

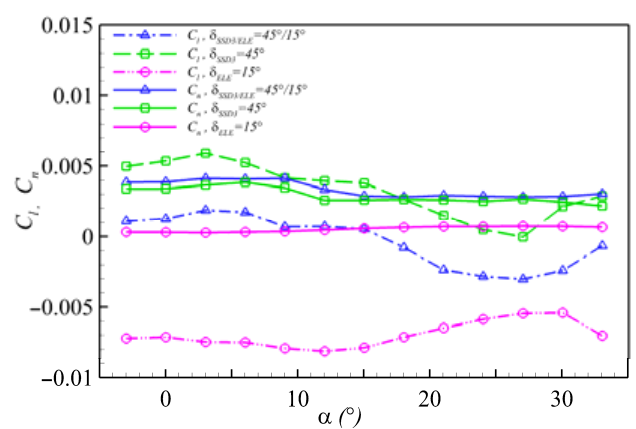

(c)

Figure 10. Yawing and rolling moments comparison of the elevon, SSDs, and corresponding FCRs, $\mathrm{Ma}=0.2, \operatorname{Re}=3.98 \times 10^{7}:$ (a) The elevon, SSD1 and the corresponding FCR; (b) The elevon, SSD2 and the corresponding FCR; (c) The elevon, SSD3 and the corresponding FCR. 
Figure 11 shows the three-axis moment characteristics of the three FCRs. In addition, Figure 11a and Table 6 show that the coupling design of FCR reduces the nose-down moments caused by the downward deflection of the elevon simultaneously. Table 7 shows the descriptions of control characteristics for the three FCRs at different $\alpha$.

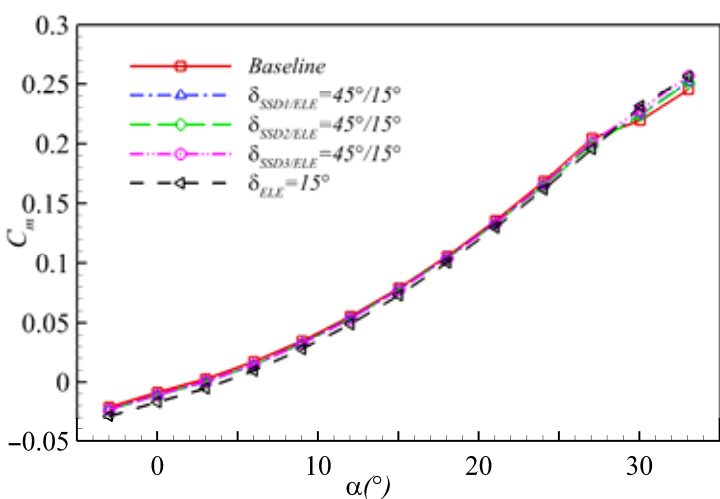

(a)

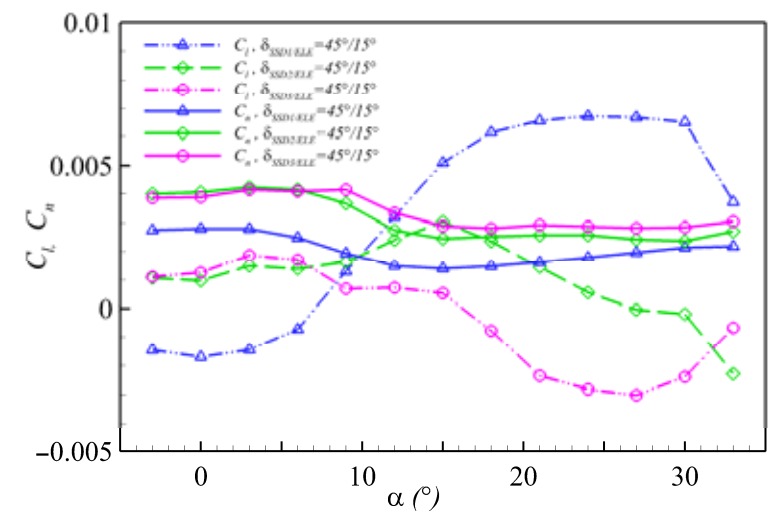

(b)

Figure 11. Control characteristics of the different FCRs for Ma $=0.2, \operatorname{Re}=3.98 \times 10^{7}$ : (a) Pitching moment; (b) Rolling and yawing moments.

Table 6. Aerodynamic moments characteristics of the FCRs at $\alpha=6^{\circ}$.

\begin{tabular}{cccc}
\hline Case & Moment & Value & $\gamma_{p}$ or $\gamma_{r}$ \\
\hline$\delta_{\mathrm{SSD} 1 / \mathrm{ELE}}=45^{\circ} / 15^{\circ}$ & $C_{n}$ & 0.00249 & - \\
& $C_{l}$ & -0.00072 & 0.29 \\
& $\triangle C_{m}$ & -0.00228 & 0.92 \\
\hline \multirow{2}{*}{$\delta_{\mathrm{SSD} 2 / \mathrm{ELE}}=45^{\circ} / 15^{\circ}$} & $C_{n}$ & 0.00414 & - \\
& $C_{l}$ & 0.00139 & 0.70 \\
& $\triangle C_{m}$ & -0.00289 & 0.34 \\
$\delta_{\mathrm{SSD} 3 / \mathrm{ELE}}=45^{\circ} / 15^{\circ}$ & $C_{n}$ & 0.00408 & - \\
& $C_{l}$ & 0.00172 & 0.63 \\
& $\triangle C_{m}$ & -0.00254 & 0.42 \\
\hline
\end{tabular}

Table 7. Descriptions of control characteristics for the three FCRs.

\begin{tabular}{|c|c|c|}
\hline \multirow{2}{*}{ Case } & \multicolumn{2}{|c|}{ Descriptions } \\
\hline & $C_{n}$ & $C_{l}$ \\
\hline SSD1/ELE & Similar trendency with SSD1 & $\begin{array}{c}\alpha \leq 6, \text { reversed; } \\
\alpha \geq 6^{\circ}, \text { a nonlinear rise trendency (not } \\
\text { conducive to turning control) }\end{array}$ \\
\hline SSD2/ELE & $\begin{array}{l}\text { Similar trendency with SSD1; } \\
\text { higher than } C_{n} \text { of SSD1/ELE }\end{array}$ & $\begin{array}{c}\alpha \leq 9^{\circ} \text { or } \alpha \geq 21^{\circ}, \text { small value, } \\
9^{\circ} \leq \alpha \leq 21^{\circ}, C_{l} \geq C_{n}\end{array}$ \\
\hline SSD3/ELE & $\begin{array}{l}\alpha \leq 9^{\circ} \text {, almost equivalent to } C_{n} \text { of } \\
\text { SSD2/ELE, } \\
\alpha \geq 12^{\circ}, \text { Larger than } C_{n} \text { of } \\
\text { SSD2/ELE. }\end{array}$ & $\mathrm{A}<18^{\circ}$, small positive value \\
\hline
\end{tabular}

The application of control surfaces changes the flow around the wing, leading to a change in the lift and drag of the entire configuration. As a result, yawing, rolling moments, and changes in the pitching moment were generated. Figure 12 shows the section streamlines of the configurations, and Figure 13 shows the Cp distribution of the sections. Figure 14 shows the spatial streamlines colored by $\mathrm{Cp}$ around SSD3 and the corresponding FCR. The downward deviation of the right elevon by $15^{\circ}$ increases the local camber of the airfoil. From the perspective of pressure distribution, the value of negative 
pressure on the upper surface increases, as well as that of the positive pressure on the lower surface; thus, the lift of the right-wing increases. The elevon is located behind the center of gravity; thus, an increase in lift will produce a nose-down moment. The deflection of the right elevon leads to an increase in induced-drag, friction-drag, and form-drag; thus, the drag of the right-wing increases. Consequently, the asymmetries of lift and drag on both sides of the configuration will produce the corresponding rolling and yawing moments.

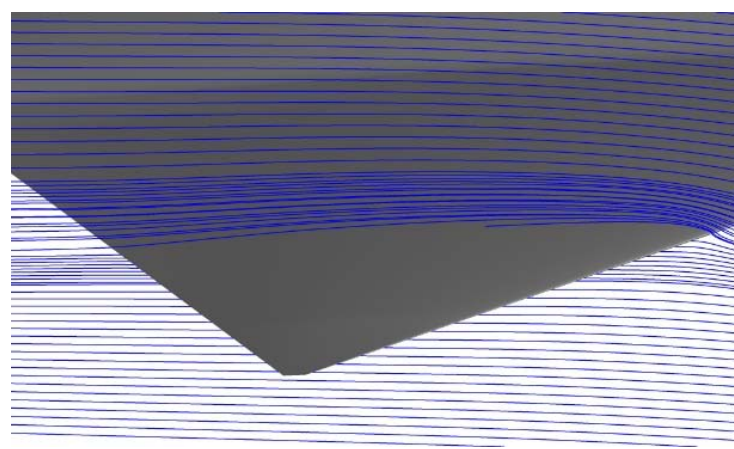

(a)

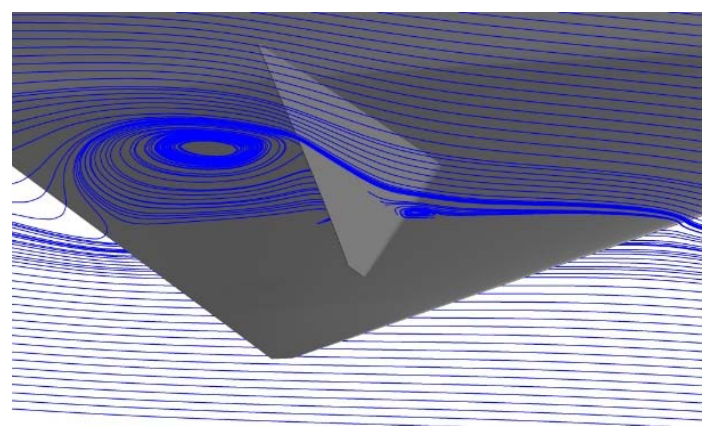

(c)

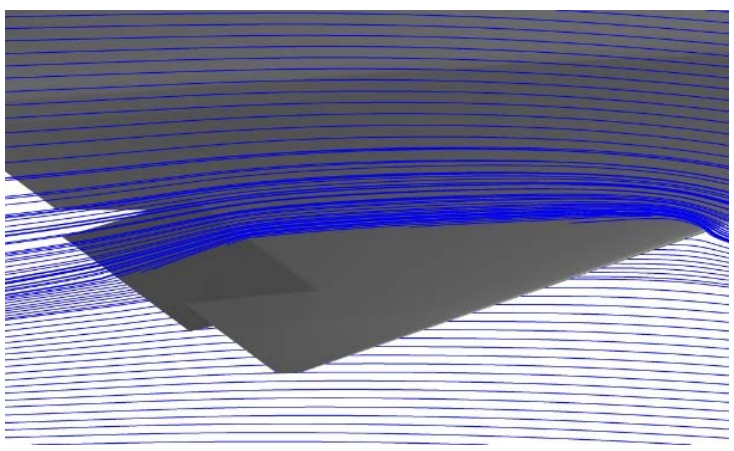

(b)

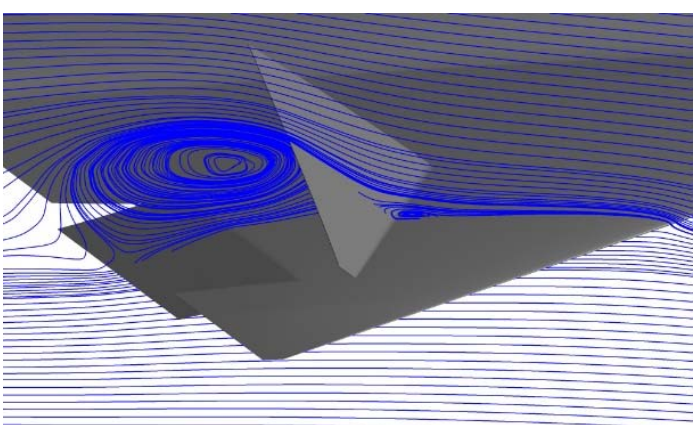

(d)

Figure 12. Section streamlines for four configurations, $\mathrm{Ma}=0.2, \operatorname{Re}=3.98 \times 10^{7}, \alpha=6^{\circ}$ : (a) Baseline; (b) Elevon; (c) SSD3; (d) FCR.

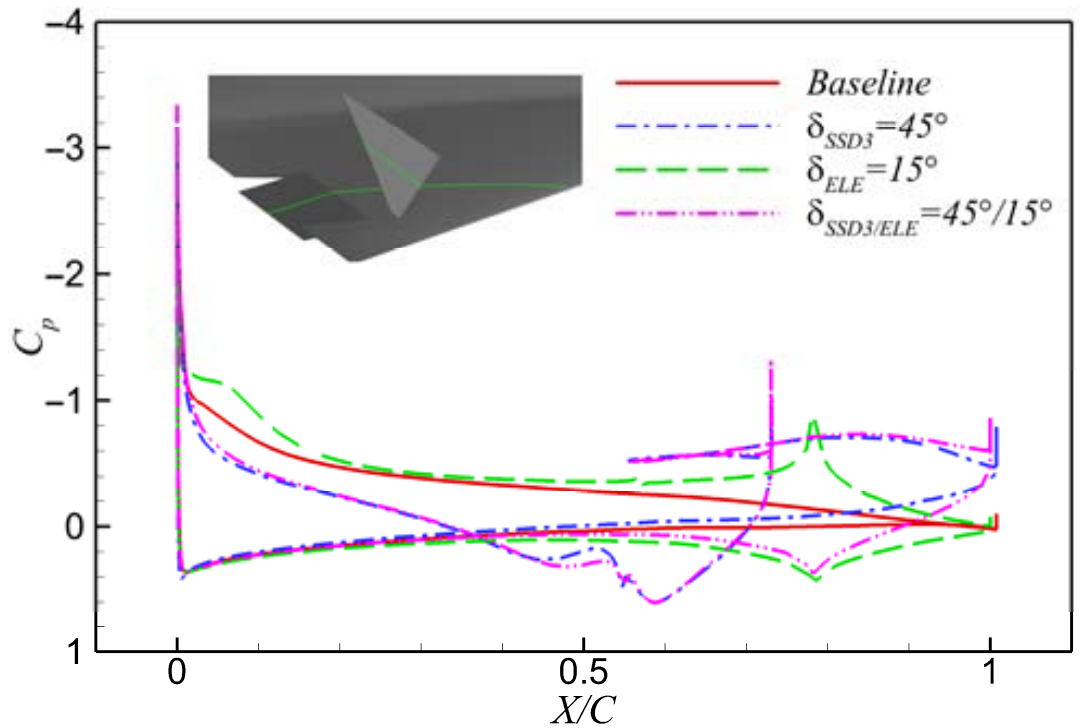

Figure 13. $C_{p}$ distribution for the sections of four configurations, $\mathrm{Ma}=0.2, \operatorname{Re}=3.98 \times 10^{7}, \alpha=6^{\circ}$. 


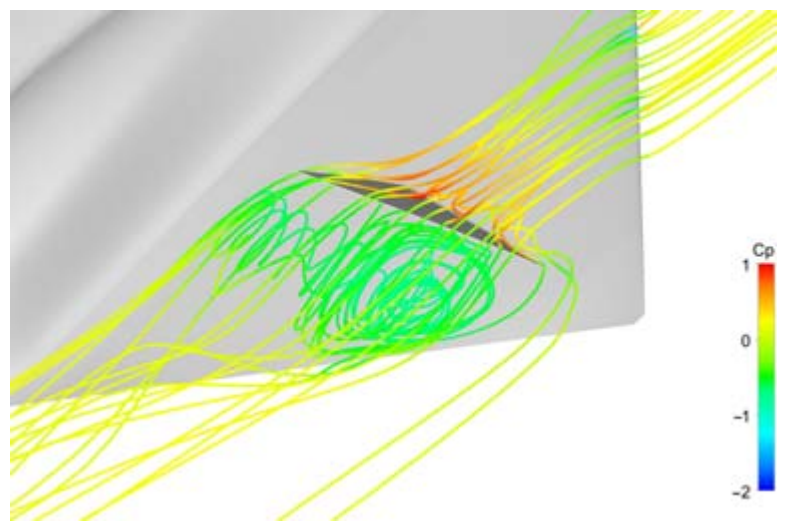

(a)

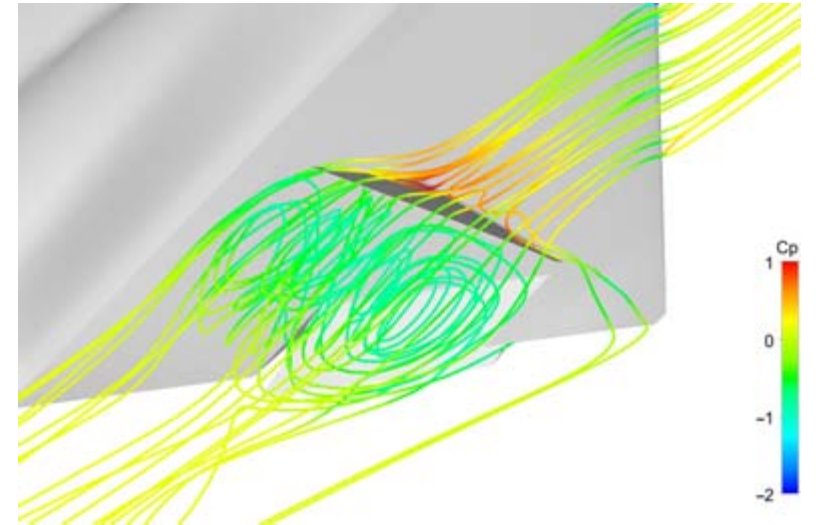

(b)

Figure 14. Spatial streamlines around the SSD3 and the corresponding FCR, Ma $=0.2, \operatorname{Re}=3.98 \times 10^{7}$, $\alpha=6^{\circ}$ : (a) SSD3; (b) The corresponding FCR.

When the SSD unfolds upward by $45^{\circ}$ alone, the windward area increases. The SSD resists the flow near the fore of the wing on the upper surface, the flow velocity decreases, the pressure increases, and the negative pressure value decreases. The closer it is to the SSD, the larger is the variation of the negative pressure on the upper surface, forming a large differential pressure drag, and the airflow fills from the edge of the SSD to its leeward area to form a separation vortex. Owing to the influence of the separation vortex, the airflow on the lower surface of the wing washes up and accelerates, reducing the pressure on the entire lower wing surface. The closer it is to the trailing edge, the more is the pressure reduction, and these flow phenomena show that when the SSD unfolds, the pressure distribution changes complexly, resulting in a change in drag and lift; hence, the change in pitching moment and rolling moment is accompanied by a change in the yawing moment.

However, when adopting the FCR, the flow characteristics are the coupling of the flow characteristics when the SSD and the elevon are adopted separately, the SSD interference is dominant on the upper surface of the wing, and the pressure distribution shape is similar to that when the SSD is adopted alone, the lower surface of the wing is dominated by the deflection of the elevon, and the pressure distribution is similar to that when the elevon is deflected alone. However, owing to the upwash effect of the separation vortex when the SSD unfolds, the pressure on the lower surface of the wing with FCR is smaller than that when the elevon is deflected alone. Table 8 lists the aerodynamic coefficients variation for the configurations at $\alpha=6^{\circ}$. The elevon and SSD can both provide a drag increasing effect and enhance the directional control ability. In addition, the lift increment caused by the elevon can offset, weakening the lift change caused by the deflection of the SSD, thus diminishing the coupled rolling moment and pitching moment.

Table 8. Aerodynamic coefficients variation for the configurations at $\alpha=6^{\circ}$.

\begin{tabular}{ccccc}
\hline Case & $\Delta \boldsymbol{C}_{\boldsymbol{L}} \%$ & $\Delta \boldsymbol{C}_{\boldsymbol{D}} \%$ & $\gamma_{p}$ & $\gamma_{r}$ \\
\hline Elevon & $11.00 \%$ & $14.49 \%$ & 23.40 & 23.78 \\
SSD & $-9.01 \%$ & $27.85 \%$ & 0.12 & 1.36 \\
FCR & $-1.53 \%$ & $38.60 \%$ & 0.42 & 0.63 \\
\hline
\end{tabular}

In summary, the FCR design concept for a low-aspect tailless configuration with a diamond-shaped wing can improve the yaw moment and reduce the coupled rolling moment and pitching moment. However, the matching parameters of SSD and elevon need to be further studied. In addition, the FCR composed of SSD3 with a sweptback leading edge and elevon can provide an efficient yawing moment at small and medium angles of attack and weaken the coupled rolling and pitching moments. 


\subsection{Location Effect of SSD3 of FCR}

Combined with the analysis in the previous section, the FCR composited of SSD3 and the elevon was selected for further study owing to its good control characteristics at small and medium angles of attack. Definition parameter $L_{n}$ : The dimensionless chord position of the outer end face of the SSD is $n$. $L_{n}$ is defined as Equation (8):

$$
L_{n}=\frac{X_{S}}{C_{S}}
$$

where $X_{S}$ is the length from the leading edge to SSD, while $C_{S}$ is the chord length of the section, as shown in Figure 15b. The positions of the SSDs are shown in Figure 15. The original parameter is $L_{0.55}$.

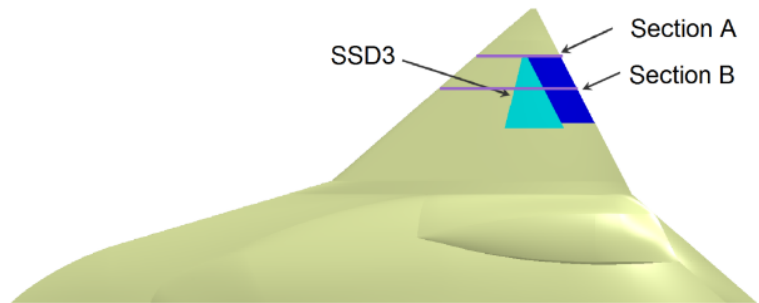

(a)

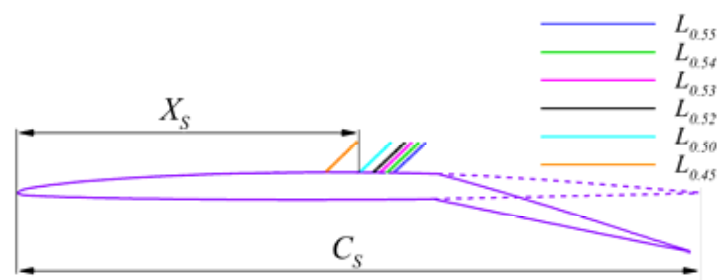

(b)

Figure 15. Position of SSD3: (a) Section location; (b) Locations of the outer end faces of SSD3 on Section A.

After the SSD moves forward, the yawing moment increases considerably because the separation area generated by the air flow bypassing the SSD is larger, and a greater drag is generated, thereby increasing the yaw moment, as shown in Figure 16. The rolling moment decreases and even reverses at small angles of attack. This is because the lift reduction caused by the forward placement of the right SSD in chordwise direction is gradually greater than the lift increment caused by the downward deflection of the elevon. According to the results, the rolling moment generated by the FCR with the SSD3 location of $L_{0.54}$ is a small right-rolling at small and medium angles of attack, and it can provide an effective yawing moment; thus, the location is selected for further study.

\subsection{Effect of Collocating Deflection Angles of the FCR}

After determining the appropriate position of SSD3, SSD3 unfolding was maintained at $45^{\circ}$, and the deflection angle of the corresponding elevon was adjusted to determine the better collocating deflection angles of the FCR. Analysis of the comparison results of yawing and rolling moments: it can be inferred from Figure 17a,b that the FCR with $\delta_{\mathrm{SSD} 3 / \mathrm{ELE}}=45^{\circ} / 14^{\circ}$ can provide an obvious right-yawing moment, and the coupled rolling moments change gently at small and medium angles of attack, and the quantity value is small and positive. Figure 18 shows the variation trend of the directional and lateral control characteristics of the FCR with the increase in the deflection angle of the elevon at different angles of attack. There is a corresponding collocating deflection angle of the FCR under different flight attitudes that provides the yawing moment when the rolling moment is eliminated. This indicates that pure directional control can be achieved.

Figure 19 shows the three-axis moment characteristics of the five groups of FCRs. The yaw moments provided by the FCRs composed of five types of collocating deflection angles are considerably greater than the rolling moments at small and medium angles of attack, while the difference in the pitching moment between the configuration with the five different FCRs and the baseline configuration is small. 


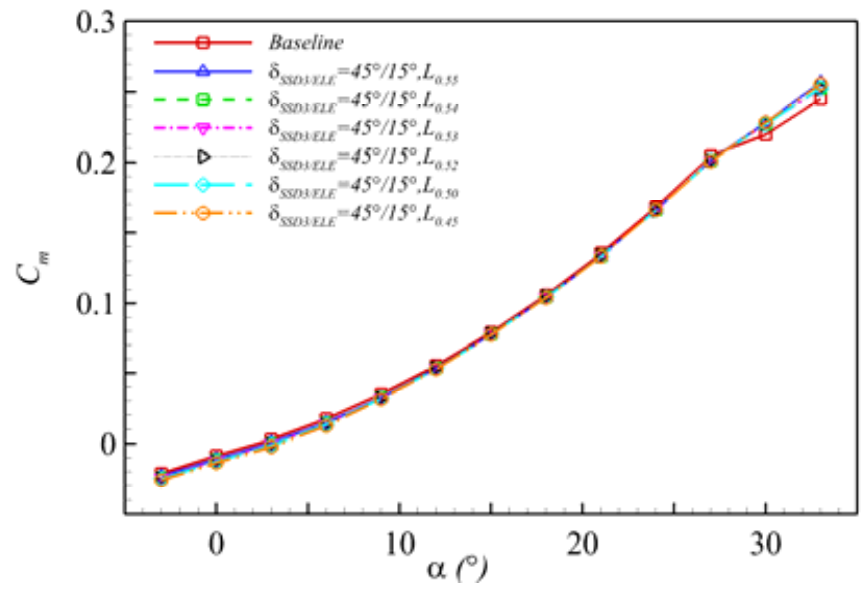

(a)

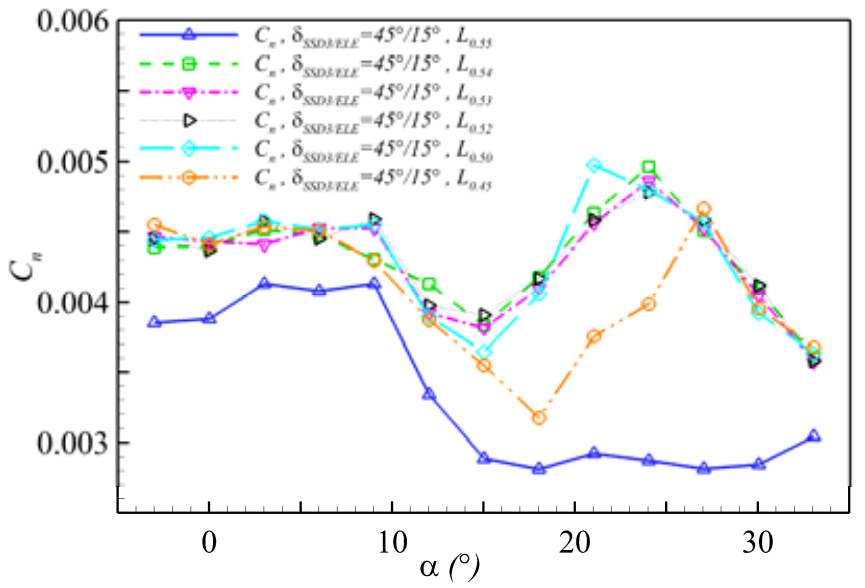

(b)

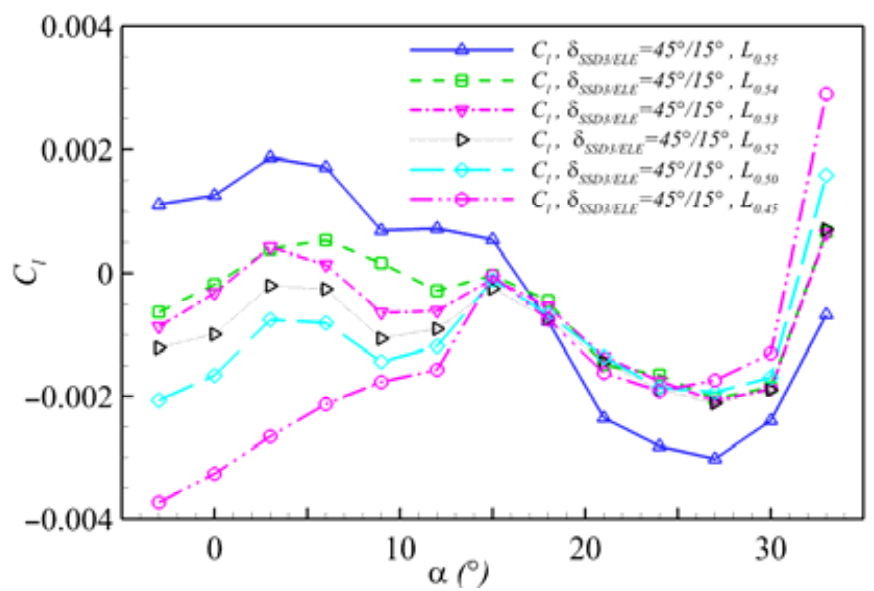

(c)

Figure 16. Control characteristics of the FCRs with different position of SSD3. $\mathrm{Ma}=0.2, \operatorname{Re}=3.98 \times$ $10^{7}$ : (a) Pitching moment; (b) Yawing moment; (c) Rolling moment.

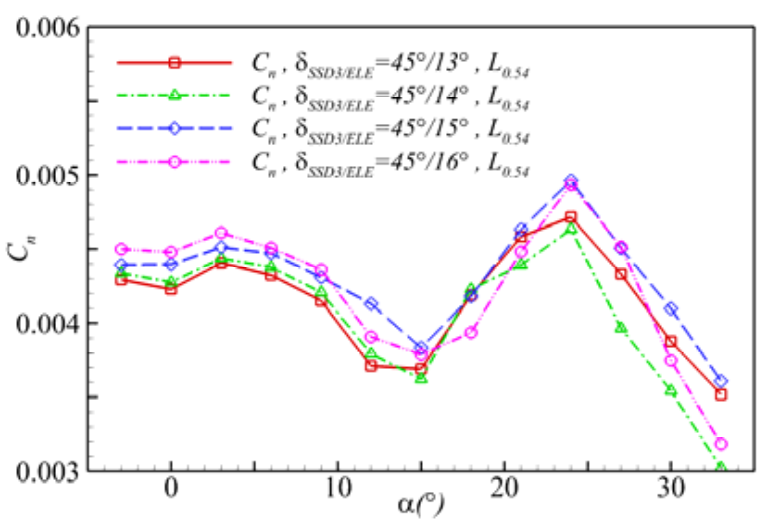

(a)

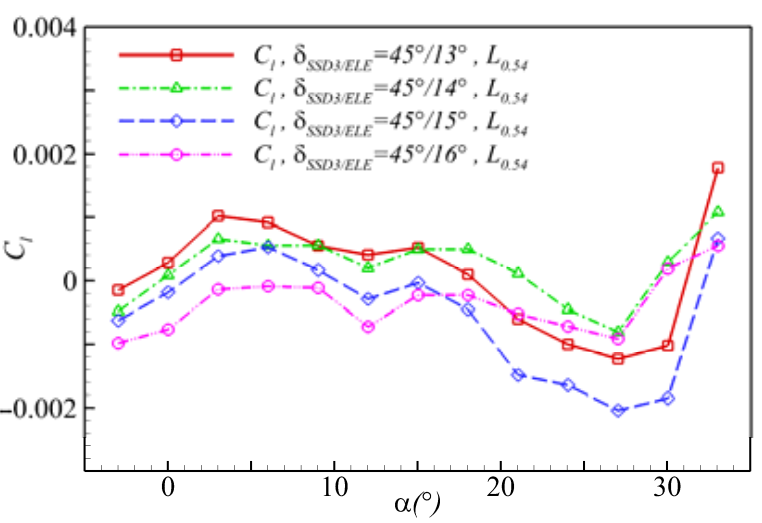

(b)

Figure 17. Control characteristics of the FCRs with different collocating deflection angles, $\mathrm{Ma}=0.2$, $\operatorname{Re}=3.98 \times 10^{7}:(\mathbf{a})$ Yawing moment; (b) Rolling moment. 


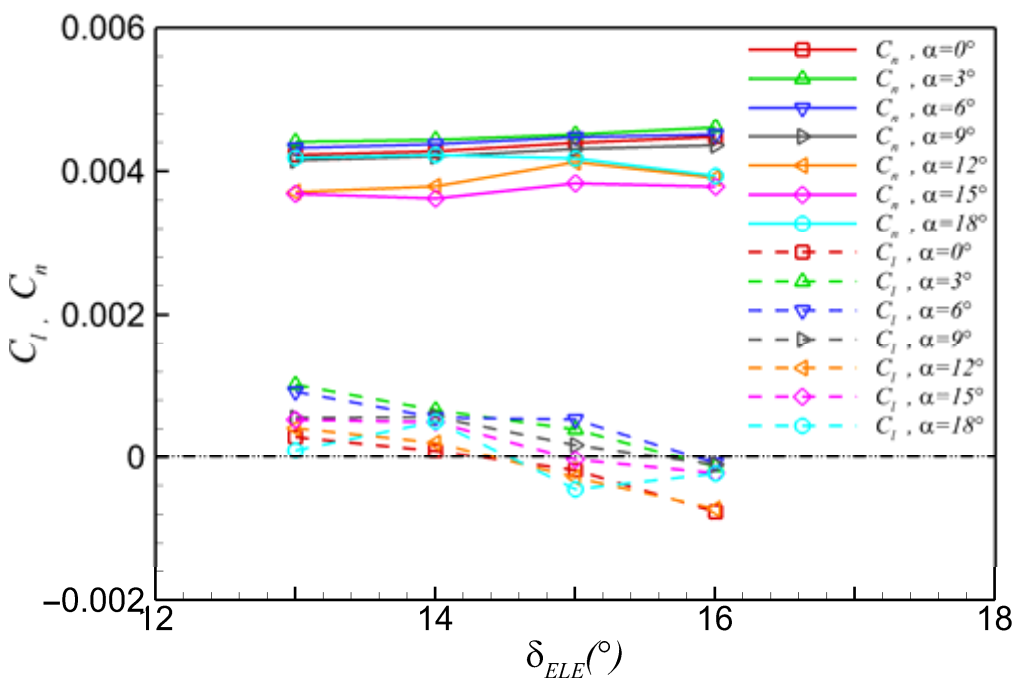

Figure 18. Variation of yawing and rolling moments with $\delta$ deflection of elevon $\left(\right.$ at $\delta$ SSD3 $\left.=45^{\circ}\right)$ at different $\alpha$.

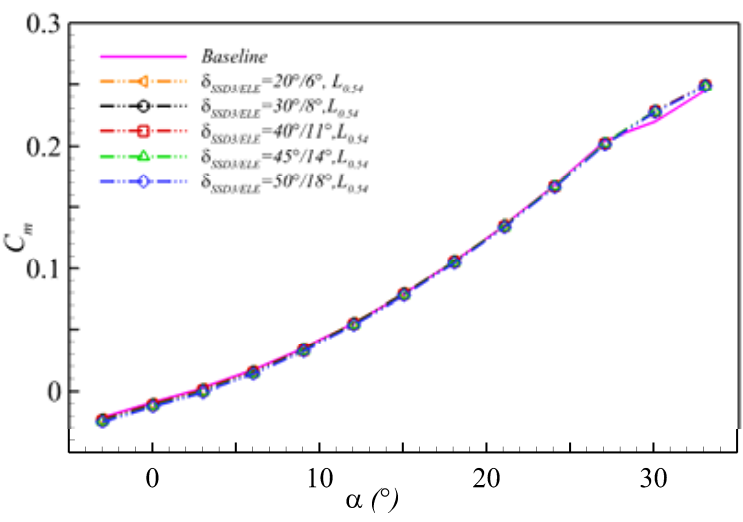

(a)

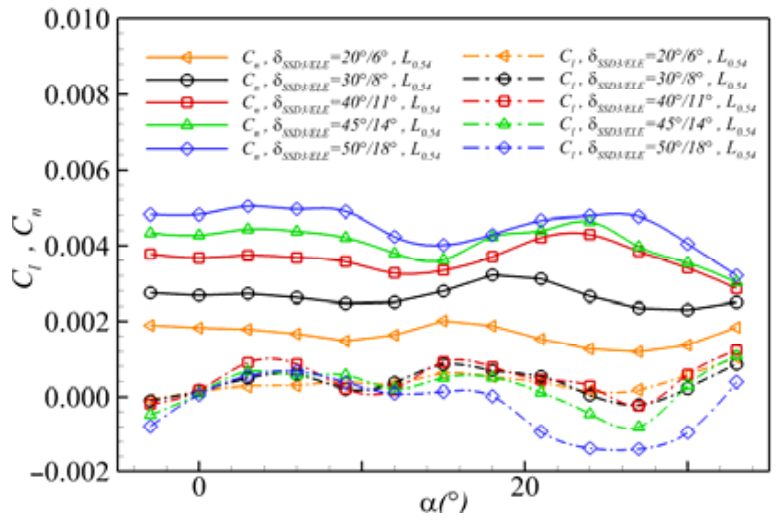

(b)

Figure 19. Control characteristics of the selected FCRs, $\mathrm{Ma}=0.2, \operatorname{Re}=3.98 \times 10^{7}$ : (a) Pitching moment; (b) Yawing and rolling moments.

The results of this section show that the FCR proposed herein can satisfy the requirements of directional stability and control of lateral maneuvering flight for a low-aspect tailless configuration with a diamond-shaped wing, and there is basically no need to compensate for the pitching and rolling moments, and under different angles of attack, pure heading control can be realized by reasonably adjusting the collocating deflection angles of FCR.

\subsection{Selection Principle of Key Parameters of FCR}

Based on the analysis in the above sections, it can be concluded that the selection principles of the FCR parameters for a low-aspect tailless configuration with the diamondshaped wing are as follows: utilizing SSD with a sweptback leading edge in the FCR can significantly improve the directional control and flight stability ability, and the leadingedge sweep angle needs to be determined according to the geometric parameters of the configuration, the position of the SSD should be moved forward appropriately, and the location should be determined by numerical analysis; for the configuration studied in this paper, in the range of $20^{\circ} \leq \delta_{\mathrm{SSD}} \leq 50^{\circ}$ and $5^{\circ} \leq \delta_{\mathrm{ELE}} \leq 20^{\circ}$, reasonably adjust collocating deflection angles of FCR, the directional stability of the maneuvering flight state can be appreciable and the coupled rolling and pitching moments can be small at $\alpha \leq 18^{\circ}$, the max yawing moment obtained can approach to about 0.005 while the coupling effect factors $\gamma_{p}$ 
and $\gamma_{r}$ are only about 0.38 and 0.11 , respectively; the rolling moment can be eliminated and the pure heading control can be realized by reasonably selecting the angles.

\section{Conclusions}

Aiming at the directional control problem of a low-aspect tailless configuration with a diamond-shaped wing, we herein selected the SSD and elevon as the basic control surfaces and carried out the study. The conclusions are as follows:

- When adopting the elevon or SSD alone, it not only provides yawing but also couples the rolling and pitching moments. It requires the cooperation of other control surfaces to reduce or even eliminate coupled moments;

- For the configuration with a diamond-shaped wing, the SSD with an appropriate sweptback leading edge is more conducive to improving the directional control and providing more stable control than the SSD with the leading edge parallel to the trailing edge of the wing;

- In terms of the configuration studied herein, adjust collocating deflection angles of FCR reasonably, the directional stability of maneuvering flight state can be increased and the coupled rolling and pitching moments can be weakened or even be eliminated at small and medium angles of attack;

- The concept of FCR for the tailless configuration could provide a satisfactory yaw moment and weaken or even eliminate the coupling pitching and rolling moments. The FCR can improve the directional control and aerodynamic moment coupling issues by only one group of control surfaces, providing more options for the other side of the control surface to participate in other controls.

The investigation presented herein can provide a method for directional control for a similar configuration. However, our study mainly focused on the low-speed directional control of a low-aspect tailless configuration with a diamond-shaped wing, and future work will be conducted on the control issue in other states such as the transonic or supersonic states. In addition, new technology based on active flow control has developed rapidly with respect to the control of aircraft, which will also be studied in the future.

Author Contributions: Conceptualization, B.Z. and Z.L.; methodology, Z.L.; software, Z.L.; validation, Z.L.; formal analysis, B.Z. and Z.L.; investigation, Z.L.; resources, Z.L.; data curation, B.Z. and Z.L.; writing—original draft preparation, Z.L.; writing—review and editing, B.Z. and Z.L.; visualization, B.Z. and Z.L.; supervision, B.Z.; project administration, B.Z.; funding acquisition, B.Z. All authors have read and agreed to the published version of the manuscript.

Funding: This research was supported by the Fundamental Research Funds for the Central Universities (Nos. 3102019JC009).

Institutional Review Board Statement: Not applicable.

Informed Consent Statement: Not applicable.

Data Availability Statement: The data presented in this study are available on request from the corresponding author.

Acknowledgments: The authors would like to deliver their sincere thanks to the editors and anonymous reviewers.

Conflicts of Interest: The authors declare no conflict of interest.

\section{References}

1. Küchemann, D. The Aerodynamic Design of Aircraft; AIAA: Reston, VA, USA, 2012; pp. 338-438.

2. Raymer, D.P. Aircraft Design: A Conceptual Approach; AIAA: Washington, DC, USA, 1989; pp. $33-47$.

3. Sang, J.H. Low-Observable Technologies of Aircraft; Aviation Industry Press: Beijing, China, 2013; pp. 57-68.

4. $\quad$ Fang, B.R. Aircraft Aerodynamic Configuration Design; Aviation Industry Press: Beijing, China, 1997; pp. 97-130.

5. Bowlus, J.A.; Multhopp, D.; Banda, S.S. Challenges and opportunities in tailless aircraft stability and control. In Proceedings of the AIAA Guidance, Navigation and Control Conference, New Orleans, LA, USA, 11-13 August 1997. [CrossRef]

6. Dorsett, K.M.; Mehl, D.R. Innovative Control Effectors (ICE); WPAFB: New Haven, CT, USA, 1996. 
7. Gillard, W.J. Innovative Control Effectors (Configuration 101) Dynamic Wind Tunnel Test Report; Air Force Research Laboratory, Wright-Patterson AFB: Dayton, OH, USA, 1998.

8. Gillard, W.J.; Dorsett, K.M. Directional control for tailless aircraft using all moving wing tips. In Proceedings of the 22nd Atmospheric Flight Mechanics Conference, New Orleans, LA, USA, 11-13 August 1997. [CrossRef]

9. Zuo, L.X.; Wang, J.J. Experimental study of the effect of AMT on aerodynamic performance of tailless flying wing aircraft. Acta Aerodyn. Sin. 2010, 28, 132-137.

10. Ward, D.T.; Stout, L.J. Use of differential leading edge flaps for lateral control at high angle of attack. In Proceedings of the 24th Aerospace Sciences Meeting, Reno, NV, USA, 6-9 January 1986. [CrossRef]

11. Li, Z.J.; Ma, D.L. Control Characteristics Analysis of Split-drag-rudder. Appl. Mech. Mater. 2014, 472, 185-190. [CrossRef]

12. Smith, C.W.; Ralston, J.N.; Mann, H.W. Aerodynamic of Forebody and Nose Strakes Based on F-16 Wind Tunnel Test Experience; Langley Research Center: Fort Worth, TX, USA, 1979.

13. Iwanski, K.P.; O’Rourke, M.J. F-15 forebody vortex flow control using jet nozzle blowing. J. Aircr. 1996, 33, 491-498. [CrossRef]

14. Hunter, C.A.; Viken, S.A.; Wood, R.M.; Bauer, S.X.S. Advanced aerodynamic design of passive porosity control effectors. In Proceedings of the 39th Aerospace Sciences Meeting and Exhibit, Reno, NV, USA, 8-11 January 2001. [CrossRef]

15. Stenfelt, G.; Ringertz, U. Lateral Stability and Control of a Tailless Aircraft Configuration. J. Aircr. 2009, 46, 2161-2163. [CrossRef]

16. Zhou, Z.; Yu, Y.G.; Liu, G.; Chen, Z.B.; Heng, K.F. Comprehensive Study on yaw control characteristic of combined control surfaces of Flying wing configuration. Acta Aeronaut. Astronaut. Sin. 2020, 41, 523422. [CrossRef]

17. Li, L.L.; Zhang, B.Q.; Li, P.F.; Zhang, M.H. Research on control technology of combined control surface for large tailless civil aircraft. Flight Dyn. 2013, 31, 450-454. [CrossRef]

18. Zhang, B.Q.; Ma, Y.; Chu, H.B.; Chen, Z.L.; Chen, Y.C. Investigation on combined control surface for yaw control of low aspect ratio flying wing configuration. Acta Aeronaut. Astronaut. Sin. 2013, 34, 2435-2442. [CrossRef]

19. Anderson, J.D. Fundamentals of Aerodynamics; McGraw-Hill Education: New York, NY, USA, 2005; pp. 19-26.

20. ANSYS. ANSYS User Manual CFX-Solver Theory Guide; ANSYS Release 18.0; ANSYS, Inc.: Canonsburg, PA, USA, 2017.

21. Rumsey, C.L.; Slotnick, J.P.; Long, M.; Stuever, R.A.; Wayman, T.R. Summary of the first AIAA CFD high lift prediction work shop. J. Aircr. 2011, 48, 2068-2079. [CrossRef]

22. Rumsey, C.L.; Gatski, T.B.; Ying, S.X.; Bertelrud, A. Prediction of high-lift flows using turbulent closure models. AIAA J. 1998, 36, 765-774. [CrossRef]

23. Sha, Z.P. Aircraft Design Manual Volume 4: Conceptual Design of Military Aircraft; Aviation Industry Press: Beijing, China, 2005; pp. 15-31.

24. Eduardo, S.; Howard, S. Conceptual design of a fifth generation unmanned strike fighter. In Proceedings of the AIAA Scitech 2019 Forum, San Diego, CA, USA, 7-11 January 2019. [CrossRef] 